\title{
Spectrum of practice in the routine management of cervical dystonia with abobotulinumtoxinA: findings from three prospective open-label observational studies
}

Vijay P. Misra ${ }^{1,4^{*}}$, Richard M. Trosch², Pascal Maisonobe ${ }^{3}$ and Savary Om ${ }^{3}$

\begin{abstract}
Background: Cervical dystonia is a heterogeneous disorder with several possible presentations, for which first-line therapy is often botulinum toxin (BoNT). In routine clinical practice the success of each BoNT injection is dependent on several variables, including individual presentation and injection technique. Large multicenter, observational studies provide important information on individualized administration strategies that cannot be otherwise ascertained from controlled clinical trials. In this meta-analysis of patient level data, we aimed to evaluate the clinical characteristics of patients with cervical dystonia undergoing routine treatment with botulinum toxin, specifically abobotulinumtoxinA. We also aimed to characterize current abobotulinumtoxinA injection techniques and parameters and to explore international differences in patient presentation and treatment.
\end{abstract}

Methods: This was a meta-analysis of baseline data from three prospective, international, multicenter, observational studies (NCT01314365, NCT00833196 and NCT01753349) of botulinum toxin treatment for the routine management of adult cervical dystonia.

Results: Data presented illustrate the significant heterogeneity of CD presentation in routine practice. Most subjects presented with a complex pattern of dystonic movements and the majority had additional components of shoulder elevation, tremor and/or jerk. Dosing was generally in accordance with that recommended in the abobotulinumtoxinA prescribing information, although the range of dosing also indicates that injections are tailored to individual presentation. Sub-group analyses at the country level revealed distinct differences in injection practice.

Conclusions: This meta-analysis is based on the largest dataset of subjects with cervical dystonia studied to date. The heterogeneity revealed in our baseline findings support the need to develop consistent, practical and comprehensive best practice guidelines.

Keywords: Botulinum toxin, Cervical dystonia, Observational study, Meta-analysis

\footnotetext{
* Correspondence: peter.misra@virgin.net

${ }^{1}$ Imperial College Healthcare NHS Trust, London, UK

${ }^{4}$ Peripheral Nerve Unit, Hammersmith Hospital, London W12 OHS, UK

Full list of author information is available at the end of the article
}

(c) The Author(s). 2018 Open Access This article is distributed under the terms of the Creative Commons Attribution 4.0 International License (http://creativecommons.org/licenses/by/4.0/), which permits unrestricted use, distribution, and reproduction in any medium, provided you give appropriate credit to the original author(s) and the source, provide a link to the Creative Commons license, and indicate if changes were made. The Creative Commons Public Domain Dedication waiver (http://creativecommons.org/publicdomain/zero/1.0/) applies to the data made available in this article, unless otherwise stated. 


\section{Background}

Cervical dystonia (CD) is the most common of the focal dystonias and is characterized by involuntary contractions of the cervical musculature and abnormal movements and postures of the head [1]. It is a heterogeneous disorder, with several possible patterns of head and neck deviations. Dystonic patterns may be 'simple', with movements limited to one plane, or 'complex', involving more than one plane. Described CD head positions include: torticollis (rotation), laterocollis (tilting), anterocollis (flexion) and retrocollis (extension) [2]. Adding to this clinical complexity, people with CD may also exhibit a variety of additional signs and symptoms, such as shoulder elevation, jerk, neck/shoulder pain and tremor [1-3]. Epidemiological studies have reported a wide range of prevalence estimates (between 28 and 183 cases/million), a female preponderance, and a mean age of onset of 42 years old [4].

Current national and international guidelines recommend chemodenervation with botulinum neurotoxin (BoNT) injections as effective therapy for the management of CD [5, 6]. The American Academy of Neurology currently recommend abobotulinumtoxin A and rimabotulinumtoxinB as having established efficacy and safety (Level A support) and should be offered as a treatment for $\mathrm{CD}$ [6]. OnabotulinumtoxinA and incobotulinumtoxin A are supported by Level B evidence and are classified as probably safe and effective for $C D$ [6]. In particular, the recommendations for abobotulinumtoxinA were based on four Class 1 randomized controlled trials (RCTs) [7-10], which have since been supplemented by data from three more trials [11-13]. However, while $\mathrm{RCTs}$ remain the preferred study design to inform clinical registration, they can be criticized as they often recruit restricted populations that are not generalizable to the wider patient population. In routine clinical practice, the success of each BoNT injection is dependent on several variables, including individual presentation and injection technique $[14,15]$. There is consensus that treatment should be targeted to the primarily affected muscles, and that injectors should consider the optimal concentration (volume of dilution), number of units and number of injections for each muscle to be injected [14]. However, aside from basic dosing recommendations given in the prescribing information, there is only limited information available to guide BoNT injection technique, and as such, decision making is often influenced by external factors such as access to treatment and injector training.

Observational studies, conducted in routine treatment settings, are useful to inform about the current management of CD including the various disease presentations, and allowing for different clinical practices. Such studies also provide important information on individualized administration strategies (e.g. dosing per muscle) that cannot be otherwise ascertained from traditional RCTs. We present here a meta-analysis of patient-level data from three prospective, observational studies to explore how abobotulinumtoxinA is used in the routine treatment of isolated CD. With data from over 1200 subjects (35 countries), it represents the largest dataset for the use of a BoNT-A formulation in CD. As such, it affords unique insights into the range of disease presentations in clinical practice as well as the characterization of current injection techniques, both nationally and internationally.

\section{Methods \\ Description of the studies}

The database includes subject baseline data from the three prospective, observational studies which have followed the course of adult CD subjects treated with BoNT-A (Table 1). The methodology and results from the individual studies have been published in detail elsewhere [16-18].

In each study, the decision to treat was taken prior to, and independently from, the decision to enroll the subject in the study. Subjects could be new to BoNT-A treatment or previously treated with BoNT-A, provided there had been at least a 12-week interval between the last injection and study entry. All subjects in each study underwent a comprehensive clinical CD assessment at baseline/first injection visit. Electronic case report forms were utilized for data collection, including data on medical history, treatment history, and details of the first injection given (e.g. muscles selected, injected dose, injected volume, number of injection sites, use of injection guidance technique). All subjects were also assessed at the baseline/first injection visit using the Toronto Western Spasmodic Torticollis Rating Scale (TWSTRS). The 'predominant' patterns of CD were per investigator judgment in the INTEREST IN CD studies and were derived from TWSTRS scores in the ANCHOR-CD study.

\section{Organization of the database}

This meta-analytic database was based on subject level baseline data from three observational studies. No other studies were considered for inclusion into the database as these are the only routine practice studies to prospectively collect injection data with abobotulinumtoxinA. All three studies used electronic case report forms, and data for each subject was checked and monitored at site by the respective Clinical Research Associates. For subjects who participated in two studies (i.e. INTEREST IN CD or ANCHOR-CD and INTEREST IN CD2), only data from the INTEREST IN CD2 study were retained for the meta-analysis. Subject level data from the three studies was merged into a single 'baseline' database, and descriptive outcomes were summarized. All outcomes 
Table 1 Studies included in database

\begin{tabular}{|c|c|c|c|c|c|}
\hline Study & Design & Setting & Subjects & Treatment & $\begin{array}{l}\text { Key assessments } \\
\text { at baseline } \\
\text { (1st injection) visit }\end{array}$ \\
\hline $\begin{array}{l}\text { ANCHOR-CD } \\
\text { (NCT01314365) } \\
{[16]}\end{array}$ & $\begin{array}{l}\text { 1-year, non- } \\
\text { interventional, } \\
\text { registry study }\end{array}$ & 41 sites in the USA & $\begin{array}{l}350 \text { adult subjects } \\
\text { with } C D\end{array}$ & $\begin{array}{l}\text { AbobotulinumtoxinA } \\
(100 \%)\end{array}$ & $\begin{array}{l}\text { - Demographics } \\
\text { - Medical history } \\
\text { - AbobotulinumtoxinA } \\
\text { injection details } \\
\text { - TWSTRS } \\
\text { - CDIP-58 } \\
\text { - PNRS }\end{array}$ \\
\hline $\begin{array}{l}\text { INTEREST IN CD1 } \\
\text { (NCT00833196) } \\
{[17]}\end{array}$ & $\begin{array}{l}\text { Non-interventional study } \\
\text { following a single BoNT-A } \\
\text { injection cycle }\end{array}$ & $\begin{array}{l}38 \text { sites across } \\
\text { Australia and Europe }\end{array}$ & $\begin{array}{l}404 \text { adult subjects } \\
\text { with CD and a } \\
\text { TWSTRS severity } \\
\text { score }>15\end{array}$ & $\begin{array}{l}\text { AbobotulinumtoxinA } \\
(69 \%) \\
\text { OnabotulinumtoxinA } \\
(28 \%) \\
\text { IncobotulinumtoxinA } \\
(3 \%)\end{array}$ & $\begin{array}{l}\text { - Demographics } \\
\text { - Medical history } \\
\text { - BoNT-A injection details } \\
\text { - TWSTRS } \\
\text { - Tsui scale (tremor) } \\
\text { - CDIP-58 }\end{array}$ \\
\hline $\begin{array}{l}\text { INTEREST IN CD2 } \\
\text { (NCT01753349) } \\
{[18]}\end{array}$ & $\begin{array}{l}\text { 3-year, non-interventional } \\
\text { study following multiple } \\
\text { BoNT-A injection cycles }\end{array}$ & $\begin{array}{l}113 \text { sites across Australia, } \\
\text { Europe, Latin America, North } \\
\text { Africa, Middle East, Asia, and } \\
\text { USA }\end{array}$ & $\begin{array}{l}1050 \text { adult subjects } \\
\text { with CD }\end{array}$ & $\begin{array}{l}\text { AbobotulinumtoxinA } \\
(69 \%) \\
\text { OnabotulinumtoxinA } \\
(24 \%) \\
\text { IncobotulinumtoxinA } \\
(6 \%)\end{array}$ & $\begin{array}{l}\text { - Demographics } \\
\text { - Medical history } \\
\text { - BoNT-A injection details } \\
\text { - TWSTRS } \\
\text { - Tsui scale (tremor) } \\
\text { - Likert scale (patient } \\
\text { satisfaction)* }\end{array}$ \\
\hline
\end{tabular}

*Only in subjects previously treated with BoNT-A

BoNT-A botulinum neurotoxin type A, CD cervical dystonia, CDIP cervical dystonia impact profile, PNRS pain numeric rating scale, TWSTRS Toronto Western Spasmodic Torticollis Rating Scale, USA United States of America

presented in this analysis were assessed and recorded at the first visit (i.e. baseline) of the three studies.

This meta-analysis focuses exclusively on abobotulinumtoxinA because each of the BoNT-A formulations has its own specific recommendations for administration in CD (doses, volume of dilution etc.) and it is well accepted that dose units are specific to the formulation and are not interchangeable [19-21]. As such, dosing and other data for each formulation should be considered separately [22]. Added to this, most subjects across the trials were treated with this formulation (ANCHOR-CD study was restricted to abobotulinumtoxinA) and only $4 \%$ of subjects were treated with incobotulinumtoxinA (in only 10 of 35 countries).

\section{Statistical analyses}

Statistical analyses of the pooled baseline data are primarily descriptive. Mean and standard deviation (mean $\pm \mathrm{SD}$ ) or median measures were used to summaries continuous variables, and absolute and relative frequencies expressed as percentage (\%) are presented for categorical information. There was no imputation for missing data. Due to concerns that some subjects treated at physiatrist sites may not actually have had isolated $\mathrm{CD}$ these baseline analyses excluded 7 physiatrist sites from the original studies (ANCHOR-CD and INTEREST IN CD2). This decision was made because interim analyses and consequent site visits identified that some subjects treated at these sites received bilateral symmetrical injections at equal doses, and injections into several muscles not involved in the dystonic postures.
Recent patient and physician surveys have indicated a range of dosing practices across different countries [23, 24]. We therefore decided to perform exploratory subgroup analyses, using data from countries with reasonable sample sizes ( $\geq 4$ active sites and data from $\geq 40$ subjects), to look for evidence of heterogeneity of national practice.

\section{Results}

\section{Subject characteristics}

These analyses include baseline data from a total of 1202 subjects with isolated CD treated with abobotulinumtoxinA at 181 neurology centers in 35 countries. Subject demographics, medical history, and clinical severity scores at Visit 1 (baseline) are presented in Table 2. Most subjects $(66 \%)$ were female and $86 \%$ were aged at least 41 years old.

The five countries with largest sample sizes were: France $(n=118)$, Germany $(n=95)$, Russia $(n=96)$, United Kingdom (UK; $n=59)$ and United States of America (USA; $n=277$ ). Roughly seven in ten subjects (68.4\%) had a complex presentation of CD (defined as having more than one pattern of $\mathrm{CD}$ ). The most common predominant head/neck patterns were torticollis and laterocollis.

\section{Injection parameters}

Data for the abobotulinumtoxinA injection parameters are summarized in Table 3. The median dose of abobotulinumtoxinA was consistently $500 \mathrm{U}$, the full range of doses indicated that injectors tailor doses to individual patient presentations. However, subgroup analyses at the 
Table 2 Demographic, medical history and clinical characteristics at baseline

\begin{tabular}{ll}
\hline Characteristic & $\begin{array}{l}\text { AbobotulinumtoxinA } \\
\text { treated subjects ( } N=1202)\end{array}$ \\
\hline Sex (female); $(\%)$ & $797(66.3)$ \\
Age; $\mathrm{n}(\%)$ & \\
18-30 & $50(4.2)$ \\
$31-40$ & $118(9.8)$ \\
$41-50$ & $261(21.7)$ \\
$51-60$ & $306(25.5)$ \\
$61-70$ & $295(24.5)$ \\
$>70$ & $172(14.3)$ \\
Proportion subjects with & $85(7.1)$ \\
CD family history; $\mathrm{n}$ (\%) & \\
Time since diagnosis (years); $\mathrm{n}(\%)$ & \\
$<1$ & $149(12.4)$ \\
1-5 & $415(34.6)$ \\
$>5$ & $637(53.0)$ \\
Missing & 1
\end{tabular}

Secondary head/neck deviation pattern and associated components; n (\%)

$\begin{array}{ll}\text { Torticollis } & 283(34.3) \\ \text { Laterocollis } & 468(56.7) \\ \text { Retrocollis } & 200(24.2) \\ \text { Anterocollis } & 151(18.3) \\ \text { Lateral shift } & 170(20.6) \\ \text { Sagittal shift } & 78(9.5) \\ \text { No secondary pattern } & 68(5.7) \\ \text { Missing/not derived } & 309 \\ \text { CD component; } n \text { (\%) } & \\ \text { Shoulder elevation; } n \text { (\%) } & 499(71.6) \\ \text { Tremor; } n \text { (\%) } & 393(56.4)\end{array}$

Table 2 Demographic, medical history and clinical characteristics at baseline (Continued)

\begin{tabular}{|c|c|}
\hline Characteristic & $\begin{array}{l}\text { AbobotulinumtoxinA } \\
\text { treated subjects }(N=1202)\end{array}$ \\
\hline Jerk; n (\%) & $86(12.3)$ \\
\hline No component & 164 \\
\hline Missing & 341 \\
\hline \multicolumn{2}{|l|}{ Tsui tremor score category; n (\%) } \\
\hline 0 & $445(47.2)$ \\
\hline 1 & $238(25.3)$ \\
\hline 2 & $155(16.5)$ \\
\hline 4 & $104(11.0)$ \\
\hline Missing & 260 \\
\hline \multicolumn{2}{|c|}{ Tsui tremor severity category; n (\%) } \\
\hline None & $445(47.2)$ \\
\hline Mild & $381(40.4)$ \\
\hline Severe & $116(12.3)$ \\
\hline Missing & 260 \\
\hline \multicolumn{2}{|c|}{ Tsui tremor duration category; n (\%) } \\
\hline None & $445(47.2)$ \\
\hline Occasional & $250(26.5)$ \\
\hline Continuous & $247(26.2)$ \\
\hline Missing & 260 \\
\hline TWSTRS Total; mean \pm SD** & $33.95 \pm 12.46$ \\
\hline TWSTRS Severity; mean \pm SD** & $17.18 \pm 5.13$ \\
\hline TWSTRS Disability; mean \pm SD** & $9.95 \pm 6.30$ \\
\hline TWSTRS Pain; mean \pm SD** & $6.82 \pm 4.94$ \\
\hline
\end{tabular}

*6 subjects had no pattern. ${ }^{* *}$ Missing data for one subject BoNT botulinum neurotoxin, $C D$ cervical dystonia, $S D$ standard deviation, TWSTRS Toronto Western Spasmodic Torticollis Rating Scale

country level revealed several national differences in injection practice. For example, while the maximum total dose given in Russia was $1000 \mathrm{U}$, some subjects in Germany and the USA received higher total doses of 1500-1600 U. Likewise, the median number of injection placement sites in the UK and France were observably lower than in Russia, the USA and Germany despite the median number of muscles injected being similar.

Overall, less than half $(41 \%)$ of subjects were injected for $\mathrm{CD}$ using a guidance technique; the most commonly used technique was electromyography (EMG; used in $39 \%$ of subjects) followed by ultrasonography $(3 \%)$ and electrostimulation (1\%). Overall, EMG was used in 467 of the 486 injections (96\%) given using a guidance technique. Of note, injectors in Germany and the USA were at least five times more likely to use an injection guidance technique than those in Russia and the UK. Analysis of time to retreatment between last injection prior to study entry and baseline injection visit for those subjects previously treated with abobotulinumtoxinA (data 
available for 385 out of 849 subjects previously treated with abobotulinumtoxinA), found that the median interval for re-treatment was 15.5 weeks, although some subjects had much longer intervals of up to 45 weeks.

The most commonly injected muscles were the splenius capitis (injected in $91 \%$ of subjects), sternocleidomastoid (81\%), trapezius (62\%), levator scapulae (47\%), semispinalis capitis (28\%) and scalene group (14\%); all other relevant muscles were injected in $<10 \%$ of subjects. These were the most commonly injected muscles regardless of whether the subject had a complex or simple presentation. Subgroup analyses at the country level identified some national trends. For example, subjects in Russia were more likely to receive injections into the trapezius (85\%) than subjects in France and Germany (46\%). In Germany and the USA, subjects were twice as likely to receive injections into the semispinalis capitis (38 and 46\%, respectively) than those in the other countries (19-24\%). Whereas injectors in the US performed scalene and longissimus group injections in about $20 \%$ of subjects, injectors in the UK did not inject into these muscles at all. The injection parameters in the top 10 injected muscles with abobotulinumtoxinA are provided in Table 4.

\section{Discussion}

This database represents the largest cohort of CD patients ever followed and provides a unique insight into how abobotulinumtoxinA is used in routine clinical practice for a broad spectrum of patients being treated for CD.

We have used baseline data to describe how patients present when they attend a routine clinic visit for ongoing or de novo treatment with abobotulinumtoxinA, and the findings showcase the significant heterogeneity of how BoNT-A is used in routine practice. Of note, the relatively unrestrictive entry criteria to the observational studies allowed us to include subjects with a broader spectrum of disease than most RCTs. This is highlighted by lower mean TWSTRS Total scores (33.95 in the present analysis vs. 43.23 in RCTs) [25], supporting the idea that RCTs often recruit subjects with more severe disease [25]. Moreover, we also observed that most patients presented with a complex pattern of dystonic movements and the majority had additional components of shoulder elevation, tremor and/or jerk. This is also in contrast to some clinical studies which have preferentially recruited patients with torticollis [26, 27], and suggests that such trial designs might have limited generalizability. As such, we suggest that large observational studies alongside RCTs have a significant place in evaluating the clinical effectiveness of a treatment in routine practice.

Dosing was generally in accordance with that recommended in the abobotulinumtoxinA prescribing information [19, 28]. The median dose was $500 \mathrm{U}$, which is also the recommended starting dose for abobotulinumtoxin $\mathrm{A}$, and evidence from long-term open-label studies have suggested that most patients with isolated $\mathrm{CD}$ continue to benefit from this dosing regimen over repeated cycles [29]. Nevertheless, clinical guidelines recommend that doses must be tailored to the patient's individual presentation, and injection parameters should be based on considerations of types of muscle (i.e. which movements they mediate), degree of abnormal muscle activity and muscle size [14]. While INTEREST in CD1 was a single cycle study, both INTEREST in CD2 and ANCHOR-CD allowed injectors to change the dosing parameters and/or muscles injected according to patient response. Future analyses of the combined database will evaluate the evolution of dosing over 1 year of repeat treatments. Nevertheless, these baseline data strongly suggests that many injectors are comfortable tailoring treatment, with some injectors going outside of the recommended dosing range of 250-1000 U. Here, the use of total doses above $1000 \mathrm{U}$ seems to be influenced by national factors with, for example, Russian injectors never going outside of the recommended dose range. Average doses per muscle were also in general alignment with current prescribing information, which provides basic guidance for injection [19, 28]. In particular, it has been suggested that unilateral injections of abobotulinumtoxinA with doses above $150 \mathrm{U}$ into the sternocleidomastoid muscle is associated with a higher dysphagia risk [29], and the median dose injected into this muscle was $130 \mathrm{U}$. However, it should be noted that the range of sternocleidomastoid dosing extended to $600 \mathrm{U}$. In this respect, it is important to note that these analyses describe how abobotulinumtoxin $A$ is currently utilized in $\mathrm{CD}$, but not how abobotulinumtoxinA should be ideally utilized in $\mathrm{CD}$. Studies comparing the effectiveness of different muscle selection and injection parameters would be needed to address this issue.

Across all countries, the most commonly injected muscles were also those most easily accessible. While these muscles are largely appropriate for torticollis and laterocollis, it is unknown if these common selections are the best choices in every patient. At the country level, our findings also revealed some differences in the frequency that certain muscles were chosen. For example, subjects in Germany and the USA appeared more likely to receive injections into the semispinalis capitis, levator scapulae and other smaller, deeper cervical muscles than other countries. This highlights the need to investigate whether injection of these muscles improves outcome. If so, more work through available training programs [30] will be required to standardize treatment paradigms. Of note, injectors in these two countries were also more likely to use injection guidance than 
Table 3 Administration of abobotulinumtoxinA at baseline (Visit 1) by country and overall

\begin{tabular}{|c|c|c|c|c|c|c|}
\hline Parameter & $\begin{array}{l}\text { Overall } \\
(\mathrm{N}=1202)^{*}\end{array}$ & $\begin{array}{l}\text { France } \\
(\mathrm{N}=118)\end{array}$ & $\begin{array}{l}\text { Germany } \\
(\mathrm{N}=95)\end{array}$ & $\begin{array}{l}\text { Russia } \\
(\mathrm{N}=96)\end{array}$ & $\begin{array}{l}\text { UK } \\
(N=59)\end{array}$ & $\begin{array}{l}\text { USA } \\
(\mathrm{N}=277)\end{array}$ \\
\hline \multicolumn{7}{|l|}{ Total aboBoNT-A dose (U) } \\
\hline Mean \pm SD & $563 \pm 245$ & $571 \pm 159$ & $647 \pm 270$ & $674 \pm 219$ & $503 \pm 163$ & $564 \pm 235$ \\
\hline Median [range] & $500[50-1700]$ & $500[200-1000]$ & $500[120-1600]$ & $500[250-1000]$ & $500[150-1150]$ & $500[100-1502]$ \\
\hline $\begin{array}{l}\text { Number of muscles injected; } \\
\text { median [range] }\end{array}$ & $3[1-11]$ & $3[1-6]$ & $4[1-10]$ & $4[2-9]$ & $3[1-6]$ & $5[1-18]$ \\
\hline \multicolumn{7}{|c|}{ Most commonly injected muscles; n (\% subjects) } \\
\hline Splenius capitis & $1087(90.4)$ & $113(95.8)$ & $87(91.6)$ & $95(99.0)$ & $52(88.1)$ & $249(89.9)$ \\
\hline Sternocleidomastoid & $967(80.4)$ & $102(86.4)$ & $83(87.4)$ & $95(99.0)$ & $44(74.6)$ & $196(70.8)$ \\
\hline Trapezius & $739(61.5)$ & $54(45.8)$ & $44(46.3)$ & $82(85.4)$ & $32(54.2)$ & $155(56.0)$ \\
\hline Levator scapulae & $569(47.3)$ & $39(33.1)$ & $55(57.9)$ & $52(54.2)$ & $28(47.5)$ & $174(62.8)$ \\
\hline Semispinalis capitis & $334(27.8)$ & $24(20.3)$ & $36(37.9)$ & $23(24.0)$ & $11(18.6)$ & $126(45.5)$ \\
\hline Scalene group** & $164(13.8)$ & $4(3.4)$ & $14(14.7)$ & $9(9.4)$ & 0 & $53(19.1)$ \\
\hline Longissimus group** & $86(7.2)$ & $4(3.4)$ & $4(4.2)$ & 0 & 0 & $57(20.6)$ \\
\hline Splenius cervicis & $60(5.0)$ & $1(0.8)$ & $3(3.2)$ & 0 & 0 & $44(15.9)$ \\
\hline Obliquus capitis inferior & $42(3.5)$ & $1(0.8)$ & $7(7.4)$ & $1(1.0)$ & 0 & $19(6.9)$ \\
\hline Platysma & $24(2.0)$ & $1(0.8)$ & $5(5.3)$ & $5(5.2)$ & $2(3.4)$ & 0 \\
\hline $\begin{array}{l}\text { Number of injection } \\
\text { points; median [range] }\end{array}$ & $7.0[1-34]$ & $4.5[1-16]$ & $8.0[2-27]$ & $9.5[4-28]$ & $4.0[1-6]$ & $9.0[1-34]$ \\
\hline $\begin{array}{l}\text { Injected volume }(\mathrm{mL}) \text {; } \\
\text { median [range] }\end{array}$ & $2.00[0.2-12.0]$ & $1.25[0.6-5.0]$ & $2.50[0.6-8.0]$ & $2.00[0.5-5.0]$ & $2.25[0.7-4.6]$ & $2.00[0.2-12.0]$ \\
\hline $\begin{array}{l}\text { Use of injection guidance; } \\
\text { n (\%) }\end{array}$ & $486(40.5)$ & $50(42.4)$ & 68 (71.6) & $12(12.5)$ & $1(1.7)$ & $166(59.9)$ \\
\hline $\begin{array}{l}\text { Interval since last } \\
\text { injection (days);:*** }\end{array}$ & $\mathrm{n} / \mathrm{N}=385 / 849$ & $\mathrm{n} / \mathrm{N}=47 / 91$ & $\mathrm{n} / \mathrm{N}=20 / 62$ & $\mathrm{n} / \mathrm{N}=31 / 76$ & $\mathrm{n} / \mathrm{N}=19 / 54$ & $\mathrm{n} / \mathrm{N}=78 / 114$ \\
\hline Median [range] & 108.3 [15.0-317.7] & $108.9[68.8-284.2]$ & $99.5[57.7-214.0]$ & $112.5[76.9-256.5]$ & $104.2[50.8-198.0]$ & $94.3[15.0-225.0]$ \\
\hline
\end{tabular}

* Missing data for one subject. * Scalene group includes muscles reported in the eCRF as scalenus or scalene (medius, anterior and/or posterior). Longissimus group includes muscles reported in the eCRF as longissimus, longissimus capitis and/or longissimus cervicis. ${ }^{* * *}$ Injection prior to study entry, where $\mathrm{N}=$ subjects previously treated with abobotulinumtoxinA only

AboBoNT-A abobotulinumtoxinA, eCRF electronic case report form, $m L$ milliliter, SD standard deviation, U units, UK United Kingdom, USA United States of America

other countries and one could speculate whether the availability (or training levels) of injection guidance techniques influences choice of muscle selection.

The most commonly injected muscles are superficial, large and easy to palpate and this may be the reason that use of injection guidance was less than $40 \%$ overall. While many injectors believe that injection guidance is not necessary for simple torticollis, it has been suggested that use of EMG to identify target muscles and guide injections is important for patients with complex forms of $\mathrm{CD}$, and especially in so called 'non-responders' or those who have suffered adverse events (e.g. related to toxin spread to adjacent muscles) [31, 32]. Using EMG guidance allows the injector to isolate the muscle fibers that are actively contracting (vs. those which are quiescent) and contributing to the dystonia. One open label trial reported that use of EMG improved the treatment outcome in 9 out of 20 subjects who had been initially identified as secondary non-responders [33]. Another study in five subjects found that use of ultrasound to guide BoNT-A injections into the sternocleidomastoid muscle eliminated the dysphagia which had previously limited the use of BoNT-A in these subjects [34]. Injection guidance is also suggested as necessary to improve accuracy of injections into the deeper or thinner neck muscles [35-37]. This advice appears to be well followed for some of the most difficult to target muscles such as the obliquus capitis inferior, for which $93 \%$ of the 42 injections recorded were given under guidance (EMG and/or ultrasonography). However, it was not as commonly used for injections into other relatively thin muscles such as the sternocleidomastoid $(<40 \%$ of injections). In their small study, Hong et al. found that the average thickness of the sternocleidomastoid is less than $1.1 \mathrm{~cm}$ (patients and controls), and suggested that potential contributors to dysphagia could be an underestimation of needle depth leading to either injection into non-target muscles or remote spread through the fascial borders of the sternocleidomastoid into the deeper neck muscles [34]. 
Table 4 Administration of abobotulinumtoxinA at baseline by muscle

\begin{tabular}{|c|c|}
\hline Muscle & $\begin{array}{l}\text { AbobotulinumtoxinA treated } \\
\text { subjects }(N=1202)\end{array}$ \\
\hline Splenius capitis & $N=1087$ \\
\hline Dose $(U) ;$ mean $\pm S D$ & $226 \pm 134$ \\
\hline Dose $(U)$; median [range] & 200 [10-1100] \\
\hline Volume (mL); median [range] & $0.75[0.1-4.4]$ \\
\hline $\begin{array}{l}\text { Number of injection points; } \\
\text { median [range] }\end{array}$ & $2[1-12]$ \\
\hline Use of injection guidance (\%)* & 40.1 \\
\hline Sternocleidomastoid & $N=967$ \\
\hline Dose $(U)$; mean $\pm S D$ & $147 \pm 81$ \\
\hline Dose $(U)$; median [range] & 130 [15-600] \\
\hline Volume (mL); median [range] & $0.50[0.1-2.8]$ \\
\hline $\begin{array}{l}\text { Number of injection points; } \\
\text { median [range] }\end{array}$ & $2[1-10]$ \\
\hline Use of injection guidance (\%)* & 38.0 \\
\hline Trapezius & $N=739$ \\
\hline Dose $(U)$; mean $\pm S D$ & $163 \pm 111$ \\
\hline Dose $(U)$; median [range] & 140 [10-1000] \\
\hline Volume (mL); median [range] & $0.50[0.1-5.3]$ \\
\hline $\begin{array}{l}\text { Number of injection points; } \\
\text { median [range] }\end{array}$ & $2[1-12]$ \\
\hline Use of injection guidance (\%)* & 34.9 \\
\hline Levator scapulae & $N=569$ \\
\hline Dose $(U)$; mean $\pm S D$ & $125 \pm 82$ \\
\hline Dose $(U)$; median [range] & $100[13-550]$ \\
\hline Volume (mL); median [range] & $0.40[0.1-2.8]$ \\
\hline $\begin{array}{l}\text { Number of injection points; } \\
\text { median [range] }\end{array}$ & $1[1-10]$ \\
\hline Use of injection guidance (\%)* & 48.9 \\
\hline Semispinalis capitis & $N=334$ \\
\hline Dose $(U) ;$ mean $\pm S D$ & $138 \pm 84$ \\
\hline Dose $(U)$; median [range] & 100 [10-500] \\
\hline Volume $(\mathrm{mL})$; median [range] & $0.50[0.1-2.2]$ \\
\hline $\begin{array}{l}\text { Number of injection points; } \\
\text { median [range] }\end{array}$ & $2[1-8]$ \\
\hline Use of injection guidance (\%)* & 49.4 \\
\hline Scalene group ${ }^{* *}$ & $N=164$ \\
\hline Dose $(U) ;$ mean $\pm S D$ & $100 \pm 68$ \\
\hline Dose $(U)$; median [range] & 85 [13-450] \\
\hline Volume (mL); median [range] & $0.30[0.1-1.5]$ \\
\hline $\begin{array}{l}\text { Number of injection points; } \\
\text { median [range] }\end{array}$ & $2[1-8]$ \\
\hline Use of injection guidance (\%)* & 50.0 \\
\hline Longissimus group ${ }^{* * *}$ & $N=86$ \\
\hline Dose $(U) ;$ mean $\pm S D$ & $128 \pm 66$ \\
\hline Dose $(U) ;$ median [range] & 100 [20-300] \\
\hline
\end{tabular}

Table 4 Administration of abobotulinumtoxinA at baseline by muscle (Continued)

\begin{tabular}{|c|c|}
\hline Muscle & $\begin{array}{l}\text { AbobotulinumtoxinA treated } \\
\text { subjects }(N=1202)\end{array}$ \\
\hline Volume (mL); median [range] & $0.40[0.0-1.2]$ \\
\hline $\begin{array}{l}\text { Number of injection points; } \\
\text { median [range] }\end{array}$ & $2[1-8]$ \\
\hline Use of injection guidance (\%)* & 64.0 \\
\hline Splenius cervicis & $N=60$ \\
\hline Dose $(U) ;$ mean $\pm S D$ & $122 \pm 79$ \\
\hline Dose $(U)$; median [range] & $100[20-500]$ \\
\hline Volume $(\mathrm{mL})$; median [range] & $0.50[0.1-1.6]$ \\
\hline $\begin{array}{l}\text { Number of injection points; } \\
\text { median [range] }\end{array}$ & $1[1-11]$ \\
\hline Use of injection guidance (\%)* & 65.0 \\
\hline Obliquus capitis inferior & $N=42$ \\
\hline Dose $(U) ;$ mean $\pm S D$ & $75 \pm 44$ \\
\hline Dose $(U)$; median [range] & 60 [20-250] \\
\hline Volume (mL); median [range] & $0.30[0.1-1.3]$ \\
\hline $\begin{array}{l}\text { Number of injection points; } \\
\text { median [range] }\end{array}$ & $1[1-2]$ \\
\hline Use of injection guidance (\%)* & 93.0 \\
\hline Platysma & $N=24$ \\
\hline Dose $(U) ;$ mean $\pm S D$ & $72 \pm 33$ \\
\hline Dose $(U)$; median [range] & $60[30-170]$ \\
\hline Volume (mL); median [range] & $0.25[0.1-0.9]$ \\
\hline $\begin{array}{l}\text { Number of injection points; } \\
\text { median [range] }\end{array}$ & $4[1-12]$ \\
\hline Use of injection guidance (\%)* & 12.5 \\
\hline
\end{tabular}

*Denominator is the number of injections into the muscle. ${ }^{*}$ Scalene group includes muscles reported in the eCRF as scalenus or scalene (medius, anterior and/or posterior). ***Longissimus group includes muscles reported in the eCRF as longissimus, longissimus capitis and/or longissimus cervicis eCRF electronic case report form, $m L$ milliliter, $S D$ standard deviation, $U$ units

Strengths of our analyses are based on its size and international reach. However, since the database includes data from subjects treated in 35 different countries, it is highly likely that the range of data reflects international differences in several factors, including access to treatment, service reimbursement (e.g. private or state funded), specialist training for injectors and patient preference. This analysis was limited to abobotulinumtoxinA, but other observational studies have confirmed the clinical utility of the other available formulations $[38,39]$. We made the decision to exclude physiatrist sites, as site visits identified that some subjects at these centers were being treated for non-dystonic conditions causing neck pain. These few subjects were included in the primary analyses of the observational studies where the objective was to report the routine use of BoNT, but excluded here because we wanted to provide clear and detailed information 
on the dosing of abobotulinumtoxinA for isolated $\mathrm{CD}$. Our analyses at this baseline stage were descriptive and no statistical comparisons were pre-planned. Future work can build on this exploratory work and test for hypothesized country-level differences in injection practices. Other limitations include those inherent to observational studies (e.g. level of missing data), as well as the recruitment of smaller subject numbers in many countries and potential site selection bias.

\section{Conclusions}

This meta-analysis of baseline data is based on the largest dataset of subjects with $\mathrm{CD}$ studied to date. We have only presented a 'snapshot' of clinical practice, but the database will continue to collect longitudinal data over several treatment cycles (repeat cycle data from INTEREST IN CD2 and ANCHOR-CD) allowing exploration of how treatment variables affect patient outcomes. For example, longitudinal analyses will allow exploration of whether different injection parameters (e.g. lower vs. higher doses, single vs. multiple injection points per muscle, small vs. large dilution volumes, use of injection guidance etc.) provide any observable benefit in terms of impact upon disease severity or treatment satisfaction. Overall, the range of our baseline findings support the need to develop consistent, practical and comprehensive best practice guidelines.

\section{Abbreviations \\ AboBoNT-A: abobotulinumtoxinA; BoNT-A: Botulinum neurotoxin type A; CD: Cervical dystonia; CDIP: Cervical dystonia impact profile; eCRF: Electronic case report form; EMG: Electromyography; PNRS: Pain numeric rating scale; RCT: Randomized controlled trial; TWSTRS: Toronto Western Spasmodic Torticollis Rating Scale; U: Units; UK: United Kingdom; USA: United States of America}

\section{Acknowledgements}

The authors wish to thank all participating sites in the three component studies, their principal investigators, sub-investigators, study coordinators as well as patients who contributed their data. We also thank Anita ChadhaPatel (ACP Clinical Communications, funded by Ipsen Pharma) for medical writing assistance.

\section{Funding}

All studies included in the database were sponsored by Ipsen Pharma who also planned and participated in the analysis of the combined dataset. The company employed two of the authors (Pascal Maisonobe and Savary Om) who participated in interpretation of data and in writing the manuscript.

\section{Availability of data and materials}

Trial data analyzed during the reported study are available to researchers. Reasonable requests should be directed to the corresponding author.

\section{Authors' contributions}

VPM acted as the principal investigator for the INTEREST IN CD1 and INTEREST IN CD2 studies, and was on the steering committee for this metaanalysis. He wrote the first draft and provided manuscript review and critique and final approval of the manuscript. RMT acted as the principal investigator for the ANCHOR-CD study and was on the steering committee for this metaanalysis. He wrote provided manuscript review and critique and final approval of the manuscript. PM is the statistician responsible for the meta- analysis. He provided manuscript review and critique and final approval of the manuscript. SO was involved in the analysis design, manuscript writing and provided full review and final approval of the manuscript.

Ethics approval and consent to participate

For each study included in this meta-analysis, Independent Ethics Committee/Institutional Review Board approval was obtained prior to each center initiation. Written informed consent was obtained prior to subject enrolment and prior to any data collection.

\section{Consent for publication}

Not applicable

\section{Competing interests}

Dr. VP Misra reports consultancy for Ipsen. Dr. RM Trosch has received personal compensation for speaking and/or consultative services from Ipsen. P Maisonobe and Dr. S Om are Ipsen employees.

\section{Publisher's Note}

Springer Nature remains neutral with regard to jurisdictional claims in published maps and institutional affiliations.

\section{Author details}

${ }^{1}$ Imperial College Healthcare NHS Trust, London, UK. ${ }^{2}$ The Parkinson's and Movement Disorders Center, 32255 Northwestern Highway, Suite 40, Farmington Hills, MI 48334, USA. ${ }^{3}$ Ipsen Pharma, 65 Quai Georges Gorse, 92100 Boulogne-Billancourt, France. ${ }^{4}$ Peripheral Nerve Unit, Hammersmith Hospital, London W12 OHS, UK.

Received: 5 April 2018 Accepted: 29 June 2018

Published online: 09 July 2018

\section{References}

1. Albanese A, Bhatia K, Bressman SB, Delong MR, Fahn S, Fung VS, et al. Phenomenology and classification of dystonia: a consensus update. Mov Disord. 2013;28(7):863-73.

2. Reichel G. Cervical dystonia: a new phenomenological classification for botulinum toxin therapy. Basal Ganglia. 2011;1:5-12.

3. Jankovic J, Tsui J, Bergeron C. Prevalence of cervical dystonia and spasmodic torticollis in the United States general population. Parkinsonism Relat Disord. 2007;13:411-6.

4. Defazio G, Jankovic J, Giel JL, Papapetropoulos S. Descriptive epidemiology of cervical dystonia. Tremor Other Hyperkinet Mov (N Y). 2013;3 tre-03-193-4374-2

5. Albanese A, Asmus F, Bhatia KP, Elia AE, Elibol B, Filippini G, et al. EFNS guidelines on diagnosis and treatment of primary dystonias. Eur J Neurol. 2011;18:5-18.

6. Simpson DM, Hallett M, Ashman EJ. Practice guideline update summary: botulinum neurotoxin for the treatment of blepharospasm, cervical dystonia, adult spasticity, and headache. Neurology. 2016;86:1-9.

7. Poewe W, Deuschl G, Nebe A, Feifel E, Wissel J, Benecke R, German Dystonia Study Group, et al. What is the optimal dose of botulinum toxin a in the treatment of cervical dystonia? Results of a double blind, placebo controlled, dose ranging study using Dysport. J Neurol Neurosurg Psychiatry. 1998;64:13-7.

8. Wissel J, Kanovsky P, Ruzicka E, Bares M, Hortova H, Streitova H, et al. Efficacy and safety of a standardised 500 unit dose of Dysport (clostridium botulinum toxin type a haemaglutinin complex) in a heterogeneous cervical dystonia population: results of a prospective, multicentre, randomised, double-blind, placebo-controlled, parallel group study. J Neurol. 2001;248:1073-8.

9. Truong D, Brodsky M, Lew M, Brashear A, Jankovic J, Molho E, et al. Longterm efficacy and safety of botulinum toxin type a (Dysport) in cervical dystonia. Parkinsonism Relat Disord. 2010;16:316-23.

10. Truong D, Duane DD, Jankovic J, Singer C, Seeberger LC, Comella CL, et al. Efficacy and safety of botulinum type a toxin (Dysport) in cervical dystonia: results of the first US randomized, double-blind, placebo-controlled study. Mov Disord. 2005;20:783-91.

11. Poewe W, Burbaud P, Castelnovo G, Jost WH, Ceballos-Baumann AO, Banach $M$, et al. Efficacy and safety of abobotulinumtoxinA liquid formulation in cervical dystonia: a randomized-controlled trial. Mov Disord. 2016;31:1649-57. 
12. Lew $M$, Snyder D. E Efficacy and safety of a $2 \mathrm{~mL}$ dilution of abobotulinumtoxinA compared with placebo in adult patients with cervical dystonia. Mov Disord. 2017;32(suppl 2) http://www.mdsabstracts.org/abstract/ efficacy-and-safety-of-a-2-ml-dilution-of-abobotulinumtoxina-compared-withplacebo-in-adult-patients-with-cervical-dystonia/. Accessed 8 Nov 2017

13. Yun JY, Kim JW, Kim HT, Chung SJ, Kim JM, Cho JW, et al. Dysport and Botox at a ratio of 2.5:1 units in cervical dystonia: a double-blind, randomized study. Mov Disord. 2015;30:206-13.

14. Albanese A, Abbruzzese G, Dressler D, Duzynski W, Khatkova S, Marti MJ, et al. Practical guidance for CD management involving treatment of botulinum toxin: a consensus statement. J Neurol. 2015;262(10):2201-13.

15. Marion MH, Humberstone M, Grunewald R, Wimalaratna S. British neurotoxin network recommendations for managing cervical dystonia in patients with a poor response to botulinum toxin. Pract Neurol. 2016;16:288-95.

16. Trosch R, Espay A, Truong D, Gil R, Singer C, LeWitt PA, et al. Multicenter observational study of abobotulinumtoxinA neurotoxin in cervical dystonia: the ANCHOR-CD registry. J Neurol Sci. 2017;376:84-90.

17. Misra VP, Ehler E, Zakine B, Maisonobe P, Simonetta-Moreau M. Factors influencing response to botulinum toxin type a in patients with idiopathic cervical dystonia: results from an international observational study. BMJ Open. 2012:2(3):e000881.

18. Misra VP, Colosimo C, Charles D, Chung TM, Maisonobe P, Om S, et al INTEREST IN CD2, a global patient-centred study of long-term cervical dystonia treatment with botulinum toxin. J Neurol. 2018;265:402-9.

19. Dysport Summary of Product Characteristics. www.medicines.org.uk/emc/ product/859/smpc. (last accessed June 2018).

20. Xeomin - Summary of Product Characteristics. www.medicines.org.uk/emc/ product/2162/smpc. (last accessed June 2018).

21. Botox 100 Units - Summary of Product Characteristics www.medicines.org. uk/emc/product/859/smpc. (last accessed June 2018).

22. Pickett $A$, Rosales RL. New trends in the science of botulinum toxin-a as applied in dystonia. Int J Neurosci. 2011;121(Suppl 1):22-34.

23. Comella C, Bhatia K. An international survey of patients with cervical dystonia. J Neurol. 2015;262(4):837-48

24. Hubble J, Schwab J, Hubert C, Abbott CC. Dysport (botulinum toxin type A) in routine therapeutic usage: a telephone needs assessment survey of European physicians to evaluate current awareness and adherence to product labeling changes. Clin Neuropharmacol. 2013;36:122-7.

25. Jen MH, Kurth H, Iheanacho I, Dinet J, Gabriel S, Wasiak R, et al. Assessing the burden of illness from cervical dystonia using the Toronto western spasmodic torticollis rating scale scores and health utility: a meta-analysis of baseline patient-level clinical trial data. J Med Econ. 2014;17:803-9.

26. Comella CL, Jankovic J, Truong DD, Hanschmann A, Grafe S, Group USXCDS Efficacy and safety of incobotulinumtoxinA (NT 201, XEOMIN(R), botulinum neurotoxin type a, without accessory proteins) in patients with cervical dystonia. J Neurol Sci. 2011;308:103-9.

27. Benecke R, Jost WH, Kanovsky P, Ruzicka E, Comes G, Grafe S. A new botulinum toxin type a free of complexing proteins for treatment of cervical dystonia. Neurology. 2005;64:1949-51.

28. Dysport (abobotulinumtoxinA) for injection, for intramuscular use. Full US prescribing information. Available at http://dysport.com. Last accessed June 2018.

29. Hauser RA, Truong D, Hubble J, Coleman C, Beffy JL, Chang S, et al. AbobotulinumtoxinA (Dysport) dosing in cervical dystonia: an exploratory analysis of two large open-label extension studies. J Neural Transm. 2013; 120:299-307.

30. Fheodoroff K, Bhidayasiri R, Jacinto LJ, Chung TM, Bhatia K, Landreau T, et al. Ixcellence network(R): an international educational network to improve current practice in the management of cervical dystonia or spastic paresis by botulinum toxin injection. Funct Neurol. 2017:32:103-10.

31. Nijmeijer SW, Koelman JH, Kamphuis DJ, Tijssen MA. Muscle selection for treatment of cervical dystonia with botulinum toxin-a systematic review. Parkinsonism Relat Disord. 2012;18:731-6.

32. Van Gerpen JA, Matsumoto JY, Ahlskog JE, Maraganore DM, McManis PG. Utility of an EMG mapping study in treating cervical dystonia. Muscle Nerve. 2000;23:1752-6.

33. Cordivari C, Misra VP, Vincent A, Catania S, Bhatia KP, Lees AJ. Secondary nonresponsiveness to botulinum toxin a in cervical dystonia: the role of electromyogram-guided injections, botulinum toxin a antibody assay, and the extensor digitorum brevis test. Mov Disord. 2006;21:1737-41.
34. Hong JS, Sathe GG, Niyonkuru C, Munin MC. Elimination of dysphagia using ultrasound guidance for botulinum toxin injections in cervical dystonia. Muscle Nerve. 2012;46:535-9.

35. Truong DMD, Dressler D, Hallett M, Pathak M, editors. Manual of botulinum toxin therapy. Cambridge: Cambridge University Press; 2009.

36. Lee $\mathrm{H}$, Yoon YC, Sung DH, Kwon JW, Jung JY. Initial experience with imaging-guided intramuscular botulinum toxin injection in patients with idiopathic cervical dystonia. AJR Am J Roentgenol. 2009;192:996-1001.

37. Schramm A, Baumer T, Fietzek U, Heitmann S, Walter U, Jost WH. Relevance of sonography for botulinum toxin treatment of cervical dystonia: an expert statement. J Neural Transm (Vienna). 2015:122:1457-63.

38. Jankovic J, Adler CH, Charles D, Comella C, Stacy M, Schwartz M, et al. Primary results from the cervical dystonia patient registry for observation of onabotulinumtoxina efficacy (CD PROBE). J Neurol Sci. 2015;349:84-93.

39. Fernandez HH, Pagan F, Danisi F, Greeley D, Jankovic J, Verma A, et al. Prospective study evaluating incobotulinumtoxinA for cervical dystonia or blepharospasm: Interim results from the first 145 subjects with cervical dystonia. Tremor Other Hyperkinet Mov. 2013;3 tre-03-139-2924-1

\section{Ready to submit your research? Choose BMC and benefit from:}

- fast, convenient online submission

- thorough peer review by experienced researchers in your field

- rapid publication on acceptance

- support for research data, including large and complex data types

- gold Open Access which fosters wider collaboration and increased citations

- maximum visibility for your research: over $100 \mathrm{M}$ website views per year

At BMC, research is always in progress.

Learn more biomedcentral.com/submissions 